\title{
Steamed Wheat Breads with Auricularia polytricha Powder as a Functional Food Product
}

\section{Fengjuan Jia1,2,3*, Yueming Wang1,2,3*, Zhiqing Gong1,2,3, Wenjia Cui1,2,3, Yansheng Wang1,2,3, Wenliang Wang1,2,3\#}

\author{
${ }^{1}$ Institute of Agro-Food Science and Technology, Shandong Academy of Agricultural Sciences, Jinan, China \\ ${ }^{2}$ Key Laboratory of Agro-Products Processing Technology of Shandong Province, Jinan, China \\ ${ }^{3}$ Key Laboratory of Novel Food Resources Processing, Ministry of Agriculture and Rural Affairs, Jinan, China \\ Email: jfj.5566@163.com,wangym1969@sohu.com, 147372843@qq.com,165703519@qq.com,296138032@qq.com, \\ "cywwl@163.com
}

How to cite this paper: Jia, F.J., Wang, Y.M., Gong, Z.Q., Cui, W.J., Wang, Y.S. and Wang, W.L. (2019) Steamed Wheat Breads with Auricularia polytricha Powder as a Functional Food Product. Open Access Library Journal, 6: e5598.

https://doi.org/10.4236/oalib.1105598

Received: July 12, 2019

Accepted: November 3, 2019

Published: November 6, 2019

Copyright $\odot 2019$ by author(s) and Open Access Library Inc.

This work is licensed under the Creative

Commons Attribution International

License (CC BY 4.0).

http://creativecommons.org/licenses/by/4.0/

\begin{abstract}
Auricularia polytricha is a functional food material that contains numerous bioactive health-promoting compounds. This study demonstrates the novel application of $A$. polytricha powder (APP) in steamed bread production. Moreover, this work aimed to determine the influence of the direct addition of APP on the sensory, textural, physical, and in vitro antioxidant properties of steamed breads. Steamed breads enriched with 5\% APP had higher consumer acceptability than those enriched with $2.5 \%, 5 \%, 7.5 \%$ and $10 \%$ APP. In addition, supplementation with APP significantly enhanced the antioxidant activity of steamed breads during digestion in vitro. Our study suggests that $A$. polytricha is a valuable source of active compounds for steamed wheat breads.
\end{abstract}

\section{Subject Areas}

Agricultural Science, Food Science \& Technology

\section{Keywords}

Steamed Bread, Auricularia polytricha, Sensory Evaluation, Texture, Antioxidant Activity

\section{Introduction}

The steamed bread is an important stable food product of the daily diet of Asian

${ }^{\star}$ These authors contributed equally to the study. 
people, especially in China. Thus, the nutritive quality of steamed bread has been an important subject for people's health. Recently steamed breads added several kinds of natural bioactive ingredients for high nutritional value and health benefits are showing great potential.

Edible mushrooms as one of most recognized and extremely popular health-promoting food materials are consumed by humans worldwide. Edible mushrooms have become increasingly important dietary food material due to low caloric content and high vegetable protein, vitamin, iron, chitin, fiber, and mineral contents, and with their nutritional, organoleptic, and pharmacological characteristics [1]. The Auricularia polytricha, known as hairy wood ear mushroom, is one of popular edible mushrooms in China [2] and the fourth harvest yield of cultivated black fungus in the world [3]. The Auricularia polytricha is often used as vegetable, and also as a functional food and medicine material because it contains numerous bioactive health-promoting compounds.

Many studies have examined the health benefits of Auricularia polytricha and its various biological activities [3]. For example, supplementation with aqueous Auricularia polytricha extract can decrease hepatic lipid accumulation and improve anti-oxidative status in rats with nonalcoholic fatty liver [4]. The soluble polysaccharide from Auricularia polytricha can decrease serum lipid concentrations to nearly normal levels and also significantly decrease total cholesterol after consumption of Auricularia polytricha for a period of time [5]. Polysaccharide SSP from the Auricularia polytricha exhibits antimutagenic activity against the in vivo DNA-damaging effect of the indirectly acting alkylating agent cyclophosphamide [6]. Auricularia polytricha polysaccharides were also shown to be potential agents winding around quantum dots (QDs) to protect DNA from damage, which is the basis for the bioeffect of polysaccharides [7]. Auricularia polytricha polysaccharides can induce cell cycle arrest and apoptosis in human lung cancer A549 cells [8].

Based on these many health benefits and high nutritional value, enormous effort has been expended to develop methods for Auricularia polytricha cultivation [9]. However, few studies have attempted to develop new food formulation of functional food products containing Auricularia polytricha as natural bioactive supplementation for high health benefits. The objective of the present study was to evaluate the influence of Auricularia polytricha as ingredient on the chemical and physical properties, sensory characteristics, in vitro antioxidant activity, and nutritional value of Auricularia polytricha-enriched steamed wheat breads.

\section{Materials and Methods}

\subsection{Preparation of Steamed Bread}

Auricularia polytricha was bought from Yutai, China. The dried Auricularia polytricha were washed thoroughly and soaked with water, then drained at room temperature and oven dried to a constant weight. After that, the dried samples were grinded into small particles by grinder and sifted through 100-mesh sieve 
to eliminate the residues, getting the fine APP for further process. The wheat flour (Shandong King Group Co., Ltd.) was purchased from Hualian Supermarket. A small-scale straight dough steaming test was conducted. APP at $0 \%, 2.5 \%$, $5 \%, 7.5 \%$, and $10 \%$ (APP adding percentage was the total quality of APP and wheat flour amount) are mixed with wheat flour, respectively. For dough preparation, flour, APP, water ( $50 \%$ on flour basis) and dried instant yeasts (equivalent to $0.3 \%$ of dry matter) were mixed in a spiral mixer for $6 \mathrm{~min}$. Then, the prepared dough was kept in a constant-temperature fermentation box for $60 \mathrm{~min}$ at $35^{\circ} \mathrm{C}$ and relative humidity of $75 \%$. The fermented dough was divided into smooth loaves with uniform sizes. The loaves were placed for $20 \mathrm{~min}$ in a constant-temperature fermentation box for second fermentation and then steamed at $100^{\circ} \mathrm{C}$ for $30 \mathrm{~min}$ in a laboratory oven. Steaming tests were performed in six replicates. Steamed bread samples were cooled for $1 \mathrm{~h}$ at room temperature $\left(25^{\circ} \mathrm{C}\right)$ and then wrapped in polyethylene bags.

\subsection{Sensory Evaluation}

Slices (approximately $1.5 \mathrm{~cm}$ thick) of steamed bread samples enriched with different percentages of APP were subjected to sensory evaluation. The steamed breads were number coded and served to consumers. The evaluation panel consisted of 25 consumers ( 20 - 40 years old, 13 females and 12 males) who evaluated the overall acceptability of steamed bread. The degree of the overall consumer preference for different types of steamed bread was determined in accordance with a nine-point hedonic scale $(1=$ dislike extremely, $5=$ neither like nor dislike, 9 = like extremely). The testers rinsed their mouths with tap water before and after testing each sample.

\subsection{Evaluation of the Textural and Physical Properties of Steamed Bread}

Bread samples were subjected to textural profile analysis $1 \mathrm{~h}$ after steaming. Steamed bread was sliced mechanically, and slices were cut from the middle portion of steamed bread $(30 \mathrm{~mm} \times 30 \mathrm{~mm} \times 25 \mathrm{~mm})$. The texture meter was TA.XP Plus (Lotun Science Co., Ltd.), using probe SMSP/36R. TPA test condition was followed: compression rate 55\%, time interval between two compression $5.0 \mathrm{~s}$, speed before test $2.0 \mathrm{~mm} / \mathrm{s}$, test speed $1.0 \mathrm{~mm} / \mathrm{s}$, speed i after test $1.0 \mathrm{~mm} / \mathrm{s}$, induction force $5 \mathrm{~g}$. Tests were conducted with 12 replicates. In a two-bite test, the samples were compressed twice (curves 1 and 2), to obtain the following textural parameters: hardness, elasticity, cohesiveness, chewiness, gumminess, and resilience.

The quality of steamed bread $(\mathrm{g})$ was measured with an electronic balance. The volume of steamed bread $(\mathrm{mL})$ was measured through steamed bread volume-meter rapeseed displacement. The specific volume of steamed bread $(\mathrm{mL} / \mathrm{g})$ was calculated as the ratio of the steamed bread volume and quantity. The $\mathrm{pH}$ of the steamed bread was measured using a $\mathrm{pH}$ meter (TESTO 206-pH2, Pruszków, Poland) with penetration probe for semi-solid substances. 


\subsection{In Vitro Digestion of Steamed Bread}

Digestion of steamed bread in vitro was determined in accordance with the method of Gawlik-Dziki with slight modifications [10]. Buffer extracts (BE) were prepared by extracting powdered samples of steamed breads $(1 \mathrm{~g})$ with $20 \mathrm{~mL}$ of phosphate-buffered salinebuffer (PBS, pH 7.4) for $1 \mathrm{~h}$. Extracts were separated by decantation, and residues were extracted again with $20 \mathrm{~mL}$ of PBS buffer. Extracts were combined and stored at $-20^{\circ} \mathrm{C}$. For the preparation of extracts after simulated digestion (GD), simulated saliva was prepared by dissolving $2.38 \mathrm{~g}$ of $\mathrm{Na}_{2} \mathrm{HPO}_{4}, 0.19 \mathrm{~g}$ of $\mathrm{KH}_{2} \mathrm{PO}_{4}, 8 \mathrm{~g}$ of $\mathrm{NaCl}$, and $100 \mathrm{mg}$ of mucin in $1 \mathrm{~L}$ of distilled water at $\mathrm{pH}$ 6.75. $\alpha$-amylase was added to obtain the enzyme activity of 200 $\mathrm{U} / \mathrm{mL}$. For the simulation of gastric digestion, $300 \mathrm{U} / \mathrm{mL}$ of pepsin in $0.03 \mathrm{M}$ $\mathrm{NaCl}$ at $\mathrm{pH} 1.2$ was prepared. Simulated intestinal juice was prepared by dissolving $0.05 \mathrm{~g}$ of pancreatin and $0.3 \mathrm{~g}$ of bile extract in $35 \mathrm{~mL}$ of $0.1 \mathrm{M} \mathrm{NaHCO}_{3}$. Samples were subjected to simulated digestion as follows: $1 \mathrm{~g}$ powdered sample was homogenized in a stomacher laboratory blender for $1 \mathrm{~min}$ to simulate mastication with $15 \mathrm{~mL}$ of simulated salivary fluid. Samples were then shaken for 10 $\min$ at $37^{\circ} \mathrm{C}$. The $\mathrm{pH}$ of the samples was adjusted to $\mathrm{pH} 1.2$ using $5 \mathrm{M} \mathrm{HCl}$. Subsequently, $15 \mathrm{~mL}$ of simulated gastric fluid was added to the samples. The samples were shaken for $60 \mathrm{~min}$ at $37^{\circ} \mathrm{C}$. After digestion with gastric fluid, the $\mathrm{pH}$ values of the samples were adjusted to $\mathrm{pH} 6$ with $0.1 \mathrm{M} \mathrm{NaHCO}_{3}$. Then, $15 \mathrm{~mL}$ of intestinal juice was added to the samples. The $\mathrm{pH}$ of the extracts was adjusted to $\mathrm{pH} 7$ with $1 \mathrm{M} \mathrm{NaOH}$. Finally, $5 \mathrm{~mL}$ of $120 \mathrm{mM} \mathrm{NaCl}$ and $5 \mathrm{~mL}$ of $120 \mathrm{mM}$ $\mathrm{KCl}$ were added to each sample. The prepared samples were subjected to in vitro digestion for $120 \mathrm{~min}$ at $37^{\circ} \mathrm{C}$ in the dark. Samples were then centrifuged and supernatants were further analyzed. Fluids obtained after in vitro digestion was transferred to dialysis sacks (D9777-100FT, Sigma-Aldrich), placed in an Erlenmeyer flask containing $50 \mathrm{~mL}$ of PBS buffer, and incubated in a rotary shaker (twice per $2 \mathrm{~h}, 37^{\circ} \mathrm{C}$ ). PBS buffer together with compounds that passed through the membrane served as an equivalent of the raw material absorbed by the intestine after digestion (GDA).

\subsection{Reducing Power Assay}

Reducing power was determined in accordance with the method of Zhang with slight modifications [11]. The reaction system contained $1.0 \mathrm{~mL}$ of extracts, 2.5 $\mathrm{mL}$ of PBS (pH 6.6, $0.2 \mathrm{M}$ ), and $1.0 \mathrm{~mL}$ of potassium ferricyanide solution ( $1 \%$, $\mathrm{w} / \mathrm{v}$ ) and was incubated for $20 \mathrm{~min}$ at $50^{\circ} \mathrm{C}$. The reaction was terminated by adding $2.0 \mathrm{~mL}$ trichloroacetic acid $(10 \%, \mathrm{w} / \mathrm{v})$. The mixture was centrifuged at $3000 \times \mathrm{g}$ for $10 \mathrm{~min}$. Then, the supernatant $(6.5 \mathrm{~mL})$ was collected and mixed with $1.2 \mathrm{~mL}$ of ferric chloride $(0.1 \%, \mathrm{w} / \mathrm{v})$. Absorbance was measured at $700 \mathrm{~nm}$ using a spectrophotometer.

\subsection{DPPH Scavenging Assay}

Free-radical scavenging activity was measured on the basis of DPPH scavenging 
activity in accordance with the method of $\mathrm{Xu}$ [12] with minor modifications. The reaction mixture contained $2 \mathrm{~mL}$ of extracts and $2.0 \mathrm{~mL}$ of DPPH solution $(0.2 \mathrm{mM})$ or ethanol $(95 \%, \mathrm{w} / \mathrm{v})$. The reaction mixture was allowed to stand for $30 \mathrm{~min}$ in the dark. Then, absorbance was determined at $517 \mathrm{~nm}$, and scavenging ability was calculated using following formula:

$$
\text { Scavenging abilities }(\%)=\left(1-A / A_{0}\right) \times 100 \%
$$

where $A$ is the absorbance of the mixture containing samples and DPPH, and $A_{0}$ is the absorbance of the mixture containing samples and ethanol.

\subsection{Hydroxyl Radical Scavenging Abilities}

Hydroxyl radical scavenging abilities were measured following the method of Zhang [13] with slight modifications. The reaction mixture, which contained 1.0 $\mathrm{mL}$ of ferrous sulfate $(9 \mathrm{mM}), 1 \mathrm{~mL}$ of salicylic acid $(9 \mathrm{mM}), 1 \mathrm{~mL}$ of hydrogen peroxide $(8.8 \mathrm{mM}, \mathrm{v} / \mathrm{v})$, and $1 \mathrm{~mL}$ of sample, was incubated at $37^{\circ} \mathrm{C}$ for $30 \mathrm{~min}$. Absorbance was measured at $510 \mathrm{~nm}$, and the hydroxyl radical scavenging ability was calculated using the following formula,

$$
\text { Scavenging abilities }(\%)=\left(1-A / A_{0}\right) \times 100 \%
$$

where $A$ is the absorbance of the samples, and $A_{0}$ is the absorbance of the blank.

\subsection{Data Analysis}

All data were expressed as the means \pm standard deviations (SD) of three replicated values. SPSS 17.0 software (SPSS, USA) was used for data analysis. Data were analyzed by one-way ANOVA, followed by Duncan's multiple-range tests to show intergroup differences. A $P$-value of $<0.05$ was considered statistically significant.

\section{Results}

\subsection{Sensory Evaluation of APP-Enriched Steamed Bread}

The steamed wheat breads with different volume fractions of APP were made and the overall view of different types of steamed bread was exhibit in Figure 1.
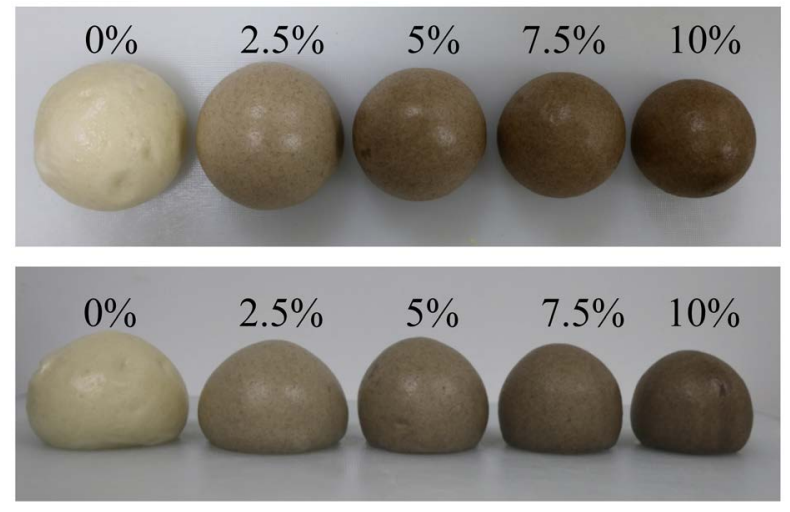

Figure 1. Overall view of APP-enriched steamed wheat bread. 
Steamed bread enriched with high amounts of APP exhibited increased color scores and decreased loaf volume. The organoleptic properties of APP-enriched steamed bread were determined as shown in Table 1. APP addition significantly influenced the sensory characteristics of the bread. The overall sensory score increased with the added amount of APP. However, the overall sensory scores decreased when more than 5\% APP was added to the bread. Increasing the added amount of APP significantly decreased color value, indicating that APP addition influenced the brightness of steamed bread. This result can be attributed to the specific black color of $A$. polytricha. Steamed bread enriched with $2.5 \%$ and $5 \%$ APP exhibited acceptable colors. The aroma and taste of steamed bread without APP addition were considered pronounced and aromatic, respectively, and APP-enriched steamed bread had a distinctive fragrance conferred by A. polytricha. The aroma and taste of steamed bread enriched with 5\% APP were highly rated by the sensory panel. Moreover, the volume of APP-enriched steamed bread decreased given the presence of small and compact pores. Breads enriched with 2.5\% and 5\% APP had high texture scores. Breads enriched with 5\% APP exhibited the highest sensory evaluation scores.

The basic properties, including $\mathrm{pH}$ and specific volume (Table 1), of APP-enriched steamed wheat bread were determined. The $\mathrm{pH}$ value of steamed bread negligibly increased with increasing volume fractions of APP. The $\mathrm{pH}$ of plain steamed wheat bread was 5.70, whereas that of steamed bread enriched with $10 \%$ APP was 5.86 . This $\mathrm{pH}$ value was considered typical and acceptable. In addition, APP enrichment decreased the volume of steamed bread, consequently decreasing specific volume.

\subsection{Textural Properties of APP-Enriched Steamed Bread}

The changes in the textural properties of different types of APP-enriched steamed bread are shown in Table 2. The hardness, chewiness, and gumminess of steamed bread linearly increased as APP content increased from $0 \%$ to $10 \%$. Changes in these textural parameters are attributable to reduced bread volume. Therefore, the addition of APP reduced the elasticity, cohesiveness, and resilience of steamed bread.

\subsection{Effect of Simulated Digestion on the Antioxidant Capacity of APP-Enriched Steamed Bread}

Reducing power and DPPH and hydroxyl radical scavenging abilities were

Table 1. Sensory evaluation and basic properties of APP-enriched steamed wheat bread.

\begin{tabular}{cccccccc}
\hline APP Addition \% & Colour & Aroma & Texture & Taste & Overall & pH-value & Specific Volume \\
\hline $0 \%$ & $8.4 \pm 0.5^{\mathrm{a}}$ & $8.7 \pm 0.3^{\mathrm{a}}$ & $8.4 \pm 0.4^{\mathrm{a}}$ & $8.4 \pm 0.5^{\mathrm{a}}$ & $8.4 \pm 0.3^{\mathrm{a}}$ & $5.70 \pm 0.31^{\mathrm{a}}$ & $2.76 \pm 0.46^{\mathrm{a}}$ \\
$2.5 \%$ & $9.3 \pm 0.9^{\mathrm{a}}$ & $8.8 \pm 0.9^{\mathrm{a}}$ & $8.8 \pm 0.4^{\mathrm{a}}$ & $8.6 \pm 0.8^{\mathrm{a}}$ & $8.6 \pm 0.7^{\mathrm{a}}$ & $5.74 \pm 0.32^{\mathrm{a}}$ & $2.56 \pm 0.63^{\mathrm{ab}}$ \\
$5 \%$ & $8.6 \pm 0.7^{\mathrm{a}}$ & $9.2 \pm 0.5^{\mathrm{a}}$ & $8.6 \pm 0.9^{\mathrm{a}}$ & $9.1 \pm 0.5^{\mathrm{b}}$ & $9.0 \pm 0.1^{\mathrm{a}}$ & $5.79 \pm 0.48^{\mathrm{a}}$ & $2.37 \pm 0.72^{\mathrm{b}}$ \\
$7.5 \%$ & $4.8 \pm 0.4^{\mathrm{b}}$ & $7.5 \pm 0.9^{\mathrm{b}}$ & $5.7 \pm 0.2^{\mathrm{b}}$ & $7.3 \pm 0.3^{\mathrm{c}}$ & $5.8 \pm 0.7^{\mathrm{b}}$ & $5.83 \pm 0.85^{\mathrm{a}}$ & $2.25 \pm 0.54^{\mathrm{b}}$ \\
$10 \%$ & $3.3 \pm 0.2^{\mathrm{b}}$ & $6.8 \pm 0.4^{\mathrm{c}}$ & $4.2 \pm 0.1^{\mathrm{b}}$ & $5.4 \pm 0.5^{\mathrm{d}}$ & $4.1 \pm 0.9^{\mathrm{b}}$ & $5.86 \pm 0.70^{\mathrm{a}}$ & $2.09 \pm 0.72^{\mathrm{b}}$ \\
\hline
\end{tabular}


Table 2. Textural properties of APP-enriched steamed wheat bread.

\begin{tabular}{|c|c|c|c|c|c|c|}
\hline APP Addition $\%$ & Hardness/g & Elasticity & Cohesiveness & Chewiness/g & Gumminess & Resilience \\
\hline $0 \%$ & $2397.1 \pm 92.4^{\mathrm{a}}$ & $0.932 \pm 0.167^{\mathrm{b}}$ & $0.782 \pm 0.155^{\mathrm{b}}$ & $1742.8 \pm 36.5^{\mathrm{a}}$ & $1873.7 \pm 28.6^{\mathrm{a}}$ & $0.407 \pm 0.068^{\mathrm{a}}$ \\
\hline $2.5 \%$ & $2994.9 \pm 18.4^{\mathrm{a}}$ & $0.914 \pm 0.083^{\mathrm{a}}$ & $0.741 \pm 0.626^{\mathrm{b}}$ & $2043.8 \pm 49.5^{\mathrm{a}}$ & $2218.2 \pm 76.7^{a}$ & $0.397 \pm 0.051^{\mathrm{a}}$ \\
\hline $5 \%$ & $4374.4 \pm 77.8^{\mathrm{b}}$ & $0.896 \pm 0.061^{\mathrm{a}}$ & $0.717 \pm 0.499^{\mathrm{a}}$ & $2840.6 \pm 80.4^{\mathrm{ab}}$ & $3160.5 \pm 78.6^{\mathrm{b}}$ & $0.375 \pm 0.038^{\mathrm{a}}$ \\
\hline $7.5 \%$ & $5767.3 \pm 63.9^{c}$ & $0.861 \pm 0.057^{\mathrm{a}}$ & $0.634 \pm 0.153^{\mathrm{a}}$ & $3375.4 \pm 43.8^{b}$ & $3817.1 \pm 36.2^{\mathrm{b}}$ & $0.366 \pm 0.065^{\mathrm{a}}$ \\
\hline $10 \%$ & $6914.2 \pm 59.4^{\mathrm{d}}$ & $0.835 \pm 0.119^{\mathrm{a}}$ & $0.615 \pm 0.341^{\mathrm{a}}$ & $4293.6 \pm 18.4^{\mathrm{c}}$ & $4989.9 \pm 10.6^{c}$ & $0.364 \pm 0.014^{\mathrm{a}}$ \\
\hline
\end{tabular}

investigated to analyze the in vitro antioxidant capacities of steamed bread. The reducing power of steamed bread enriched with $0 \%-10 \%$ APP is depicted in Figure 2(a). The results showed that the reducing power of APP-enriched steamed bread is a dose-dependent response. In BE stage, the reducing power of plain steamed bread was relative lower. Steamed bread enriched with 10\% APP had a highest reducing power. During the GD stage, the reducing power of all kinds of steamed bread is approximately $10 \%-20 \%$ higher than that in BE, and all the tested steamed bread exhibited dose-dependent reducing power. The reducing power of APP-enriched steamed bread at the GDA stage was lower than that in BE and GD stage. The DPPH scavenging abilities of the breads are shown in Figure 2(b). DPPH scavenging abilities increased in a dose-dependent manner with APP content. During the GD stage, DPPH radical scavenging abilities were considerably higher than those at BE. All tested steamed bread had detectable but low DPPH radical scavenging abilities during the GDA stage. As shown in Figure 2(c), steamed bread enriched with $1 \%-10 \%$ APP had stronger scavenging hydroxyl scavenging activity than the control bread. Similar to reducing power and DPPH scavenging abilities, hydroxyl scavenging abilities were higher during the GD stage and lower during the GDA stage.

\section{Discussions}

Edible mushrooms, A. polytricha, a common mushroom species cultured in northern China, is an excellent source of vitamins, minerals, fiber, carbohydrates, and antioxidants. Moreover, it exhibits antitumor, antioxidant, and immunomodulatory activities. The steamed bread is a traditional staple food in China. Especially in the Northern part of China, almost $70 \%$ of wheat is used to produce steamed breads. However, wheat flour loses large amounts of vitamins, dietary fiber, and other nutrients during processing. Thus, the long-term consumption of processed wheat flour and wheat flour products may cause nutritional imbalances. The health properties and antioxidant activities of steamed wheat breads can be improved through supplementation with powder of $A$. polytricha.

APP is a valuable source of active compounds that can enhance the nutritive value of steamed wheat breads. Steamed bread enriched with 2.5\% APP also had the highest texture score out of all bread samples. Higher level of APP addition drastically decreased color, aroma, texture, and taste scores. APP-enriched 


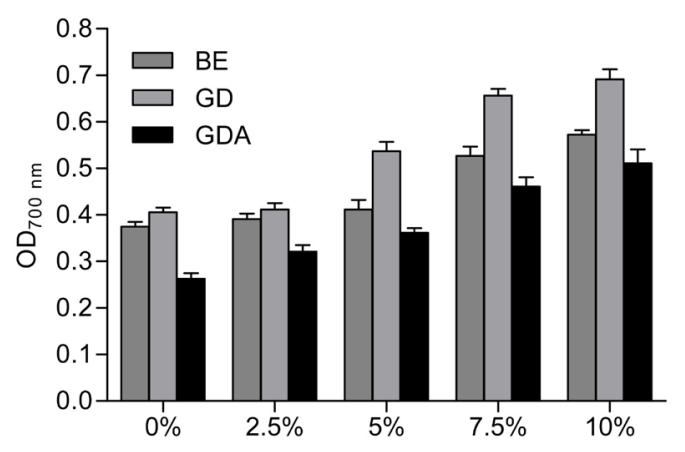

(a)

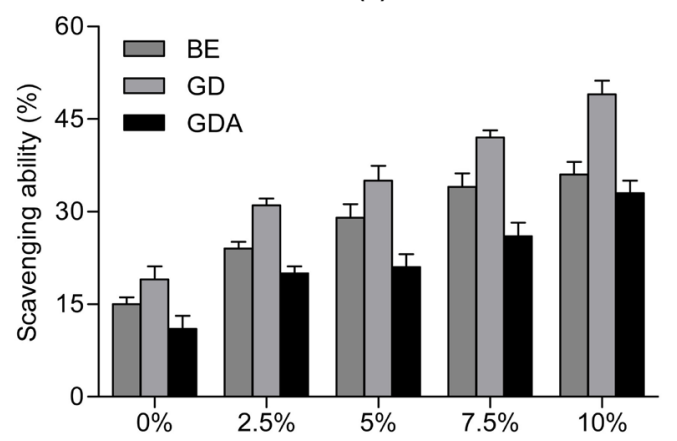

(b)

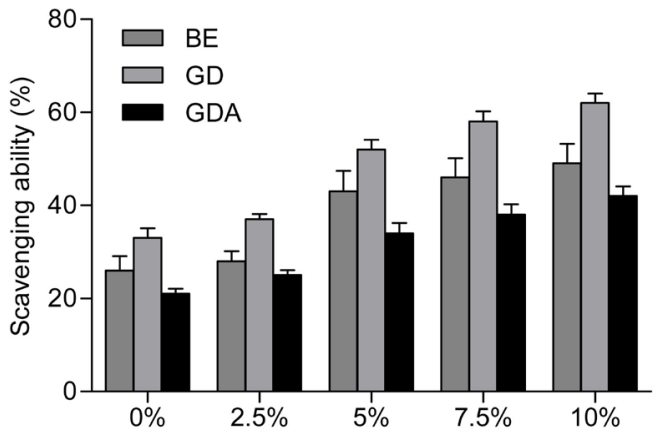

(c)

Figure 2. In vitro antioxidant activities of APP-enriched steamed wheat bread. (a) Reducing power; (b) DPPH radicals; and (c) Hydroxyl radicals. BE: buffer extract, GD: extract after digestion in vitro, and GDA: extract after absorption in vitro. Values are presented as mean \pm SD of three independent technical replicates. Mean values with different letters in superscript within the same column are significantly different $(P<0.05)$.

steamed bread has improved nutritive properties and antioxidant activity. Moreover, steamed wheat bread enriched with 5\% APP received satisfactory overall consumer acceptability, suggesting that APP-enriched steamed bread could serve as a functional food for the supplementation of daily diets. Results suggested that these changes in textural parameters are also a consequence of reduced bread volume. Gluten, a kind of colloid mixed protein, is the skeleton and the peculiar constituent of the dough. Hardness and chewiness are two important indexes to evaluate the quality of flour products. Within a certain range, the hardness and chewiness are inversely proportional with the softness of dough. The reason of APP addition increasing the hardness and chewiness is that the protein and dietary fiber of APP hindered the formation of gluten net- 
work. The gluten elasticity and ductility of steamed bread are poorer, leading to reduced air chamber and the increased hardness, and chewiness. However, consumers found that steamed bread samples enriched with $7.5 \%$ and $10 \%$ APP were almost completely unacceptable. These results may be attributed to the negative effects of excessive amounts of APP compounds on the sensory and textural characteristics of the product.

The in vitro digestion model which simulates the physiological processes occurring in the gastrointestinal tract of the human digestive system has been widely used to study the complex multistage process of human digestion. These models deliver a beneficial choice to animal and human models by quickly screening food components. In the present study, the antioxidant activity of the APP-enriched wheat bread samples was determined before and after an in vitro digestion. Reducing power and DPPH and hydroxyl radical scavenging abilities were widely recognized as antioxidant index to analyze antioxidant capacities in vitro. Our results indicated that the antioxidant activities of APP-enriched wheat bread were increased after digestion, and almost consistent with these antioxidant contents. These results may be partially explained by interactions between food matrix components (especially between phenolics, proteins, and starch) and components of gastrointestinal fluid. Moreover, though the best in vitro digestion technique would offer precise results in a short time and would help supply systems for different components and structure, the in vitro digestion model was difficult to fully simulate the complex digestive environment in the body. Further studies are necessary to address the correlation between the release of biologically active compounds from solid matrices under physiological conditions and the basic cellular properties of antioxidant activities.

\section{Acknowledgements}

This work was supported by the Key Research and Development Plan of Shandong Province (Grant No. 2017GNC13106), Natural Science Foundation of Shandong Province (ZR2016CB24), and Science Foundation of Shandong Academy of Agricultural Sciences (2016YQN58) in China.

\section{Conflicts of Interest}

The authors declare no conflicts of interest regarding the publication of this paper.

\section{References}

[1] Guillamon, E., Garcia-Lafuente, A., Lozano, M., D’Arrigo, M., Rostagno, M.A., Villares, A., et al. (2010) Edible Mushrooms: Role in the Prevention of Cardiovascular Diseases. Fitoterapia, 81, 715-723.

https://doi.org/10.1016/j.fitote.2010.06.005

[2] Peng, W., He, X., Wang, Y., Zhang, Y., Ye, X., Jia, D., et al. (2014) A New Species of Scytalidium Causing Slippery Scar on Cultivated Auricularia polytricha in China. FEMS Microbiology Letters, 359, 72-80. https://doi.org/10.1111/1574-6968.12564 
[3] Chellappan, D.K., Ganasen, S., Batumalai, S., Candasamy, M., Krishnappa, P., Dua, K., et al. (2016) The Protective Action of the Aqueous Extract of Auricularia polytricha in Paracetamol Induced Hepatotoxicity in Rats. Recent Patents on Drug Delivery \& Formulation, 10, 72-76. https://doi.org/10.2174/1872211309666151030110015

[4] Chiu, W.C., Yang, H.H., Chiang, S.C., Chou, Y.X. and Yang, H.T. (2014) Auricularia polytricha Aqueous Extract Supplementation Decreases Hepatic Lipid Accumulation and Improves Antioxidative Status in Animal Model of Nonalcoholic Fatty Liver. Biomedicine, 4, 12.

[5] Zhao, S., Rong, C., Liu, Y., Xu, F., Wang, S., Duan, C., et al. (2015) Extraction of a Soluble Polysaccharide from Auricularia polytricha and Evaluation of Its Anti-Hypercholesterolemic Effect in Rats. Carbohydrate Polymers,122, 39-45. https://doi.org/10.1016/j.carbpol.2014.12.041

[6] Zhou, J., Chen, Y., Xin, M., Luo, Q., Gu, J., Zhao, M., et al. (2013) Structure Analysis and Antimutagenic Activity of a Novel Salt-Soluble Polysaccharide from Auricularia polytricha. Journal of the Science of Food and Agriculture, 93, 3225-3230. https://doi.org/10.1002/jsfa.6161

[7] Wang, W., Zhang, G. and Zou, J. (2013) The Interaction of Polysaccharide from Auricularia polytricha with Quantum Dots and the Protection of Plasmid DNA from Damage. Applied Biochemistry and Biotechnology, 169, 2263-2272. https://doi.org/10.1007/s12010-013-0135-0

[8] Yu, J., Sun, R., Zhao, Z. and Wang, Y. (2014) Auricularia polytricha Polysaccharides Induce Cell Cycle Arrest and Apoptosis in Human Lung Cancer A549 Cells. International Journal of Biological Macromolecules, 68, 67-71. https://doi.org/10.1016/j.ijbiomac.2014.04.018

[9] Abd Razak, D.L., Abdullah, N., Khir Johari, N.M. and Sabaratnam, V. (2013) Comparative Study of Mycelia Growth and Sporophore Yield of Auricularia polytricha (Mont.) Sacc on Selected Palm Oil Wastes as Fruiting Substrate. Applied Microbiology and Biotechnology, 97, 3207-3213.

https://doi.org/10.1007/s00253-012-4135-8

[10] Gawlik-Dziki, U., Swieca, M., Dziki, D., Seczyk, L., Zlotek, U., Rozylo, R., et al. (2014) Anticancer and Antioxidant Activity of Bread Enriched with Broccoli Sprouts. BioMed Research International, 2014, Article ID: 608053. https://doi.org/10.1155/2014/608053

[11] Zhang, J., Meng, G., Zhai, G., Yang, Y., Zhao, H. and Jia, L. (2016) Extraction, Characterization and Antioxidant Activity of Polysaccharides of Spent Mushroom Compost of Ganoderma lucidum. International Journal of Biological Macromolecules, 82, 432-439. https://doi.org/10.1016/j.ijbiomac.2015.10.016

[12] Xu, N., Gao, Z., Zhang, J., Jing, H., Li, S., Ren, Z., et al. (2017) Hepatoprotection of Enzymatic-Extractable Mycelia Zinc Polysaccharides by Pleurotus eryngii var. Tuoliensis. Carbohydrate Polymers, 157, 196-206. https://doi.org/10.1016/j.carbpol.2016.09.082

[13] Zhang, C., Li, S., Zhang, J., Hu, C., Che, G., Zhou, M., et al. (2016) Antioxidant and Hepatoprotective Activities of Intracellular Polysaccharide from Pleurotus eryngii SI-04. International Journal of Biological Macromolecules, 91, 568-577. https://doi.org/10.1016/j.ijbiomac.2016.05.104 